\title{
Nurses' Perceptions of Nursing as a Profession and Its Impact on Their Intention to Leave Their Career: Staff Nurses in Jeddah City
}

\author{
Shafeah Makdour Aljedaani ${ }^{1}$ \\ ${ }^{1}$ (Nursing Specialist, Supervisor of Nursing Research and Development in Nursing Administration in Jeddah \\ Province, Kingdom of Saudi Arabia)
}

\begin{abstract}
Nurses play a vital role in the healthcare system, providing continuous 24-hour care to hospitalized patients. Nurses have also established themselves as an essential element of other disciplines within the hospitals. Despite the significant role of the nursing staff, there is a shortage of nurses worldwide. Hospitals in the Ministry of Health in Saudi Arabia are facing notable deficiencies in staffing. The present quantitative study assessed Saudi nurses' perceptions of nursing as a profession to determine the reasons that may lead to nursing staff turnover. A questionnaire consisting of two parts was administered, with the first part eliciting demographic information and the second asking questions related to the nurse's perceptions, the reasons that may lead to nursing turnover and factors to improve the retention of nurses, their point of view, and suggestions. The sample comprised 350 nurses of both genders, selected randomly. The study was conducted at three Saudi Arabian government hospitals (King Fahd Hospital, King Abdulaziz Hospital, and Althager Hospital). The results show that most participants perceived nursing positively, as most (59.1\%) felt proud to be a nurse. However, 55.5\% believed that the nursing profession would be not suitable for their children. Additionally, $76.0 \%$ of them confirmed that they were not satisfied with their career ladder or the financial benefits of a nursing career. The results of this study illustrate statistically significant variations among the responses regarding nurses' satisfaction with their career ladder and the financial benefits of the nursing profession related to employment systems. This study found that nurses in autonomously operated health facilities had a higher satisfaction related to their career ladder and the financial benefits in comparison with the nurses on civil service system. The main recommendation is to improve the physical and psychological aspects of nurses' work environment.
\end{abstract}

Keywords: Perceptions, Nursing Profession, Retention, Shortage, Turnover.

\section{Introduction}

Nurses represent the largest proportion of workers in the healthcare sector. They provide continuous, direct nursing care to hospitalized patients around the clock. Their main focus is the patient's condition, and it is generally accepted that nurses play a significant role in the hospital setting. Nevertheless, the shortage of nurses is a global issue. Therefore, the nursing shortage is a major challenge facing the healthcare sector [1].There has been an increase in the number of Saudi nurses working in the Ministry of Health in the Kingdom of Saudi Arabia in both employment systems. The civil service system which the nurses are employed by ministry of civil service and the autonomously operated health facilities which the nurses employed by the health facilities itself and renewing their contract on annual basis. In 2015 the rate of Saudi nurses in ministry of health it was $60.14 \%$ [2]. Yet the nursing shortage continues to be a problem.

According to the World Health Organization, healthcare sectors worldwide are facing nursing shortages [3]. In line with this, [4] reported that Saudi Arabia loses 50\% of its nursing graduates annually due to social and professional factors. Thus, the shortage of nurses in general, and those working in hospitals in particular, is a growing concern. In 2015, 101 nurses from hospitals in Jeddah Province requested to transfer their services, with 84 of them wanting to move to public health centers [5].

Hospitals in Saudi Arabia are currently facing a significant problem, as they employ a considerable number of new nurses, in place of experienced non-Saudi nurses, in order to achieve their Saudization targets [5]. This prioritization of Saudis is the result of the second Gulf War (1990), when a large number of experienced non-Saudi nurses left the country proving suddenly, which had disastrous consequences. Nevertheless, achieving the Saudization of the profession is to be a long process [6]. Moreover, newly qualified nurses are not selecting the nursing profession as a potential career path, and many experienced nurses are leaving the field [1]. Every nurse in every setting has the opportunity to make a positive impact on the profession by advocating daily for nurses and the nursing profession [7]. Therefore, nurses' perceptions of their profession have an important value in creating a clear framework for the nursing profession. 
[8] defined perception as "The ability to see, hear, or become aware of something through the senses." Nurses' satisfaction with the benefits and advantages of their career, and respect and appreciation from their employer, have a role in shaping their perceptions of the nursing profession and have a profound impact on nurse retention and turnover. There are many factors that may affect the nurses' perceptions of their profession and their decision to leave the profession. Studies have shown that $39.7 \%$ of nurses left their work due to family reasons and $37.3 \%$ for other reasons, and one of the main reasons for the current shortage of nurses is the community's perception of nurses $[9,10]$.

According to [11], when nurses perceived their public image to be poor, in addition to a lack of professional recognition at work, their intention to leave their job tended to increase. Evidently, to enhance nurses' job performance and reduce their turnover intention, it is important to improve both the perception in the community and nurses' self-perception. The nursing profession needs to be clarified to the community in order for the latter to understand nurses' roles and the vital tasks that they perform.

Nurses in particular, and health workers in general, have always been under observation by patients, members of the community, and the media, because they are involved with a most valuable factor-namely, human health. "Although nurses comprise the majority of healthcare professionals, they are largely invisible. Their competence, skill, knowledge, and judgment are as the word 'image' suggests—only a reflection, not reality" [12]. The nursing profession does not receive appreciation or support from Saudi tribal families, as they believe that the profession brings shame to the family and the tribe. Therefore, they direct their children to other professions, such as medicine and education. In addition, they consider the profession unsuitable for women, as it exposes them to interactions with men and working long hours and night shifts[13].

Accordingly, the work environment is another important reason for the nursing turnover rate. [14] found that nurses' intention to leave their profession increased when they lacked support in the work environment and when the demands of the profession overlapped with their family life. Moreover, [15] stated that nurses' intention to leave the profession or change their career was caused by dissatisfaction with salaries and shift work. They found it taxing to reconcile their work schedule and personal life. The work environment comprises the psychological and physical environments, established through the interactions of the staff with the organization [16]. A good workplace is characterized by low levels of stress and employees feeling appreciated by management and not feeling threatened at work [17]. A study conducted in the Makkah region, which includes the cities of Makkah, Jeddah, and Taif, uncovered that nurses who work in general hospitals were dissatisfied with their work [18]. The importance of the relationships within the nursing team, when nurses experience high-quality exchanges with their fellow team members. As these relationships solidify, nurses become more satisfied with their job and feel a greater sense of belonging to the hospital, and this minimizes the nursing staff's intention to leave [19]. There are a number of nurses who believe that the image of the nursing profession is affected by many factors, such as what is displayed and published about nursing in the media and advertising, and each individual's level of education. Nurses can also have a significant effect on the nursing image in how they present themselves every day during daily nursing care. However, the greatest influence on the image of nursing comes from the personal interactions between nurses, patients, and those participating in other disciplines in the workplace, from family and relatives' encouragement, and the presence of a family member working in the same hospital $[20,21,22]$. The positive perceptions of nurses regarding the nursing profession result from their job satisfaction and sense of belonging to their profession. Nurses can promote a positive image of their profession through adopting a caring and constructive approach both in the hospital and in the community. [21] reported that nurses play a major role in building a good image of their profession during the daily interactions, communications, appearance, and behaviors of nurses when they perform their tasks and provide nursing care. Nurses also represent their profession outside the work environment and in their personal lives because, as soon as they say that they are a nurse, people perceive them differently and most likely have specific expectations.

[23] found a significant direct relationship between nurses' caring behaviors and patient satisfaction. Nurses' communication while providing care is the most important behavior in caring for hospitalized patients. In addition, the relationship between the caring practices and patient satisfaction shows that positive nurses' behaviors lead to the improvement of patients' perceptions of healthcare and increased satisfaction with it. In this study, the researcher aimed to uncover nurses' perceptions of their profession and also identify the reasons why nurses may choose to leave the nursing profession. The study was undertaken in the three largest general hospitals in the Jeddah region, which have been experiencing nursing shortages and high staff turnover. Most studies have focused on the perceptions of patients and community members regarding the nursing profession and have paid less attention to the nurses' own perceptions of their profession.In fact, nurses are the ones who are best able to determine the causes of staff turnover and who can suggest appropriate retention strategies. The objective of this study was to give nursing administrators and organizations a clear indication of how nurses perceive their profession and the factors that may lead to these perceptions. The findings of the study have produced recommendations for enhancing the positive view of nurses toward the profession and for determining how to retain staff in the nursing profession. 


\section{Research Question:}

How do professional nurses in government hospitals (King Fahd Hospital, King Abdulaziz Hospital and Althager Hospital) in the Jeddah city perceive their profession and its impact on their intention to leave the nursing career?

\section{Research Aim:}

To assess how professional nurses in government hospitals (King Fahd Hospital, King Abdulaziz Hospital, and Althager Hospital) in the Jeddah city perceive their profession and its impact on their intention to leave the nursing career.

\section{Research Objectives:}

1. To assess how professional nurses perceive their profession.

2. To determine the reasons that may lead to nurses' turnover.

3. To identify the factors that may improve the retention of nurses and thereby prevent nursing turnover.

\section{Material and Methods}

This paper presents a cross-sectional descriptive study using a quantitative approach. The study was conducted in three Saudi Arabian government hospitals under the Ministry of Health in the city of Jeddah. The Jeddah city was chosen because the researcher works in nursing administration, which is responsible for the nurses who work in these hospitals. The target of the study was Saudi nurses working in King Fahd Hospital, King Abdulaziz Hospital, and Althager Hospital. These specific hospitals were selected because they are the largest general hospitals in Jeddah, with each reporting frequent nurse turnover and staff expressing the intention to leave the job after complaining of a shortage of nurses for many years.

\section{Research Methodology}

The research methodology is a broader concept than the research method. The research methodology entails the discussion of how the survey will be carried out through determining the population and sample of the study, the methods used in the administration of the survey, and the suitable statistical techniques and models used to analyze the collected data. As stated by [24], the research methodology is a way to systematically solve the research problem; it may also be understood as a science of studying how research is done scientifically and the logic behind it.

As [25] argued, the research methodology is intended to describe how to translate the research perspective on the way of studying the world. The research methodology may be implemented through several different research designs, such as the plan for conducting the study, through translating the research methodology into specific research methods and the techniques used to collect and analyze the data [25]. Hence, this study involved the use of a descriptive method in the presentation of information that has been collected through a primary data source.

\section{Research Methods}

As [24] described, research methods may be understood as all those methods or techniques that are used to conduct research. The research methods have been classified into three groups: [25]

1. The first group includes methods that are concerned with data collection. These methods are used when the data are insufficient to arrive at a conclusion.

2. The second group consists of those statistical techniques that are used for establishing relationships between the data and the unknowns.

3. The third group consists of those methods that are used to evaluate the accuracy of the results obtained.

The last two groups are generally regarded as the analytical tools of research.

Based on the above, the researcher constructed a questionnaire as an instrument to collect quantitative data in order to answer the research question. The designed questionnaire method consisted of information regarding the selected sample of the study, known as demographic factors, and the other components of the questionnaire that were aimed at measuring nurses' perceptions regarding the nursing profession.

\section{Sampling}

The sample size was 350 nurses of both genders ( 99 male, 251 female), selected randomly. The sample only included Saudi nurses because there is a shortage of Saudi nurses in the hospitals. Besides the frequent turnover of nursing staff, Saudi Arabia seeks to "Saudize" the nursing profession, as the practice of contracting non-Saudi nurses to cover this shortage in nursing is common. For this reason, non- Saudi nurses were excluded from this study. The Sample Size Calculator Program was used to distribute the samples among the intended hospitals [26]. 


\section{Setting}

This study was conducted at the three largest general hospitals in Jeddah city This study was carried out during the 2016: King Fahd Hospital, King Abdulaziz Hospital, and Althager Hospital. Accordingly, subjects were recruited from these hospitals to participate in the study. King Fahd Hospital, the oldest and largest hospital of the three, is located in the northern part of Jeddah city and has a capacity of 727 beds and 1500 staff nurses. King Abdulaziz Hospital, the second largest hospital, is located in the southern part of Jeddah city and has a capacity of 576 beds and 919 staff nurses. Lastly, Althager Hospital is located in the far southern region of Jeddah city and has a capacity of 150 beds and 230 staff nurses.

\section{Measures/Instruments}

Using the findings from the literature review, the researcher developed the questionnaire. It comprised three parts: Part I contained sociodemographic data, including gender, age, marital status, and level of education; Part II focused on the perceptions of nurses regarding the nursing profession; and Part III included nurses' perceptions regarding other issues related to the nursing profession. A focus group was used to establish tool validity. The pilot study involving 22 nurses was undertaken to evaluate the questionnaire and to report the nurses' comments and any difficulties they may have had with the questionnaire. The questionnaire was modified according to their answers and distributed in its final form among a large random sample.

\section{Statistical Techniques for the Data Analysis}

The data collected were entered and processed using the Statistical Package for Social Sciences (SPSS) version 20. Descriptive and inferential statistical techniques have been used to analyze the collected data. These techniques include frequencies, percentages, mean average, standard deviations, in addition to T-Test and ANOVA.

\section{Ethical Considerations}

Research ethics approval was obtained from the research ethics committee of the Directorate of Health Affairs in Jeddah Province. In addition, approval was obtained from the hospitals where the research was carried out.

- Fully informed participants freely consented to participate in the research.

- All the processes of this research were carried out within the ethical and legal frameworks.

\section{Data Analysis}

Data were collected through a questionnaire administered to a sample of nurses selected randomly from the three hospitals.

The detailed data analysis was conducted as follows:

1) Demographic characteristics of the sample

2) Nurses' perceptions of the nursing profession

3) Comparisons between nurses' perceptions to measure significant variations attributed to gender, marital status, education level, graduation, and years of experience

\section{Analysis of demographic characteristics}

Figure 1.Sample distribution according to the hospital

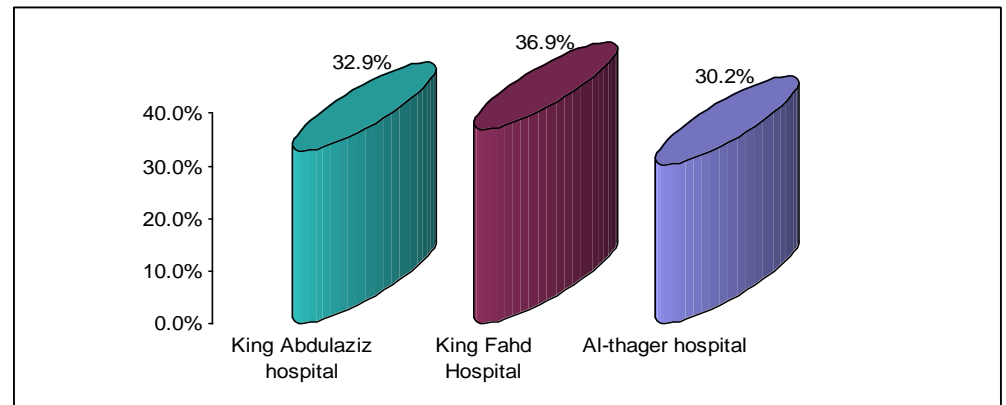

The statistics in the above figure show participants distribution according to hospital; it can be seen that the participants were quite evenly distributed between the three hospitals. 
Figure (2) the sample subject of the study distribution according to gender

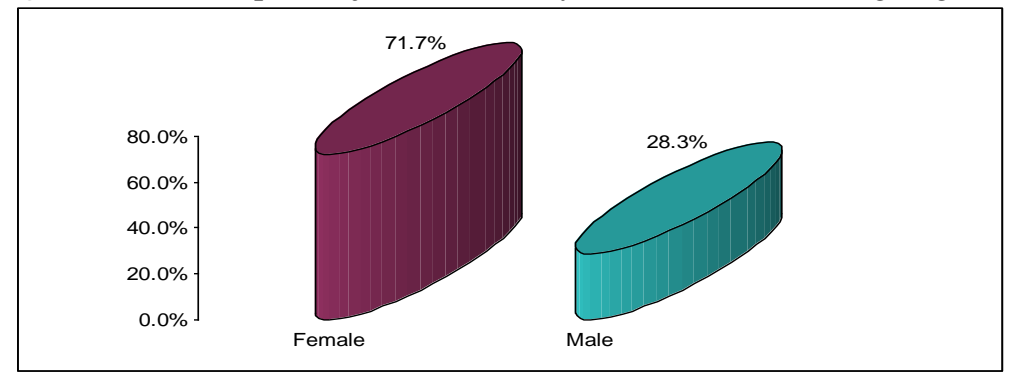

From the above figure, it is clear that female nurses comprised the majority of the participants with $71.7 \%$, with male nurses representing only $28.3 \%$.

Figure (3) Sample distribution according to age classes

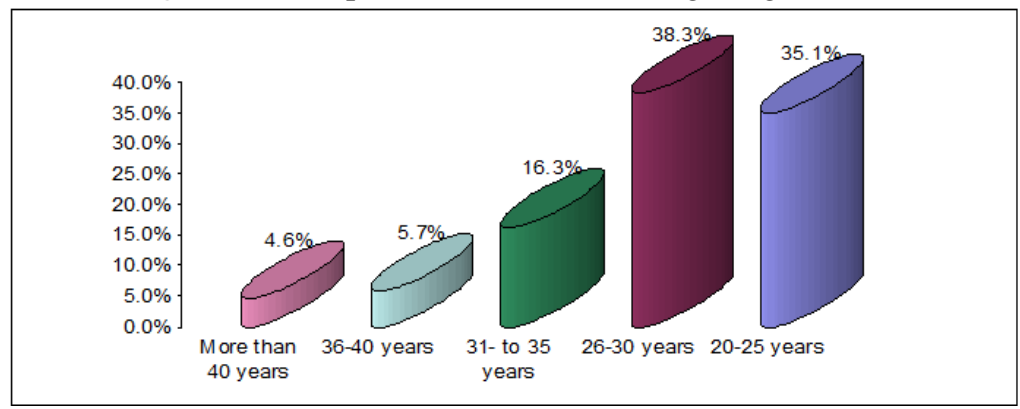

From the statistics in the above figure, indicate that the majority of sample were in the younger age.

Figure (4) the nurses sample distribution according to marital status

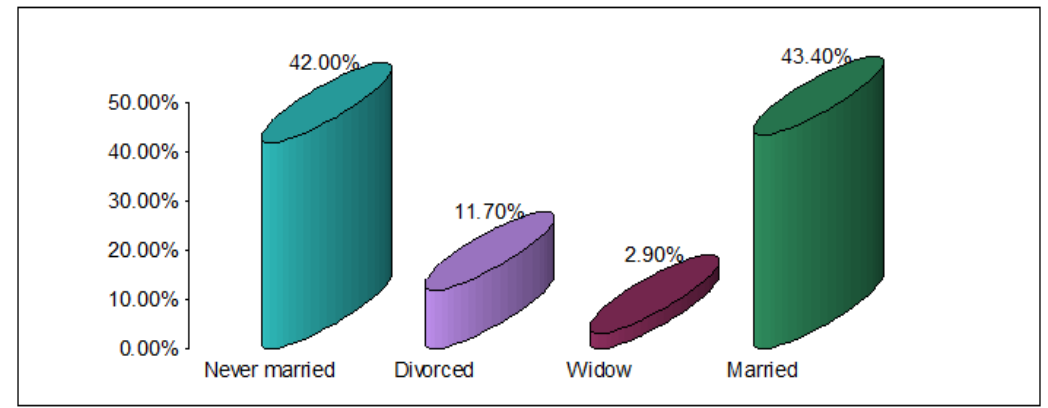

The above figure illustrates that the married and never married nurses represented the majority of participants in the study, which indicted different views might be reflected in the study due to differences in personal life experiences regarding the nursing profession.

Figure (5) the nurses sample of the study distribution according to employment systems

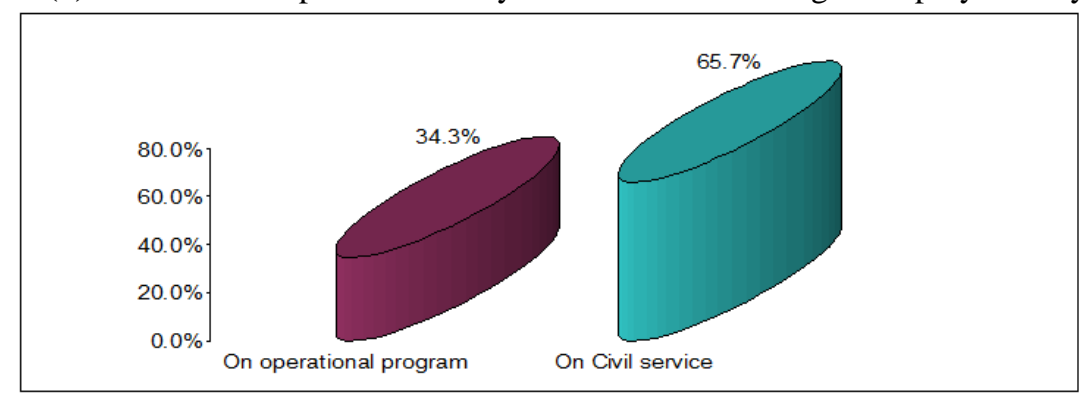

The statistics in the above figure showed the participants distribution according to employment systems and it is clearly indicated that the majority are employed in the civil service (65.7\%), whereas those employed on operational programs represented about $34.3 \%$. 
Figure (6) the nurses sample distribution according to educational level

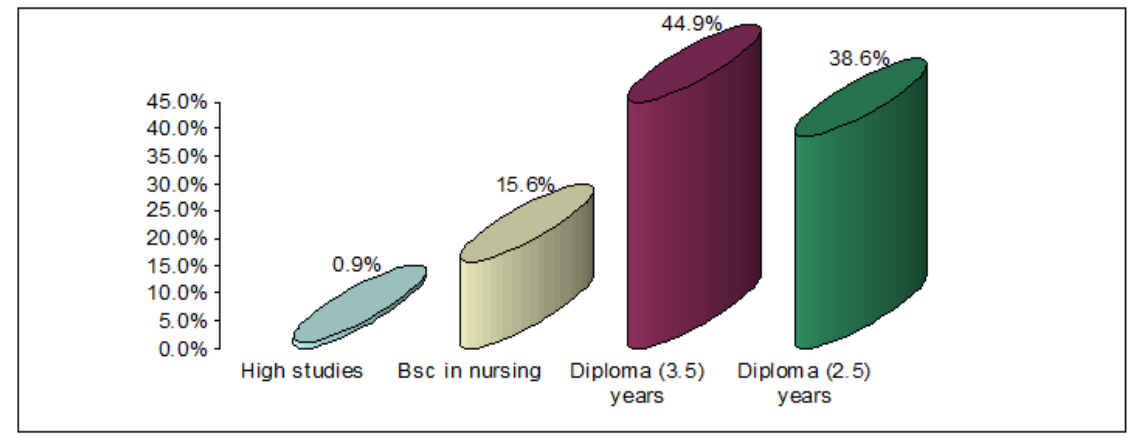

Figure (6) shows that holders of nursing diplomas represent the majority of participants in the study with $83.5 \%$ percent of the total sample.

Figure (7) the nurses sample of the study distribution according to graduation

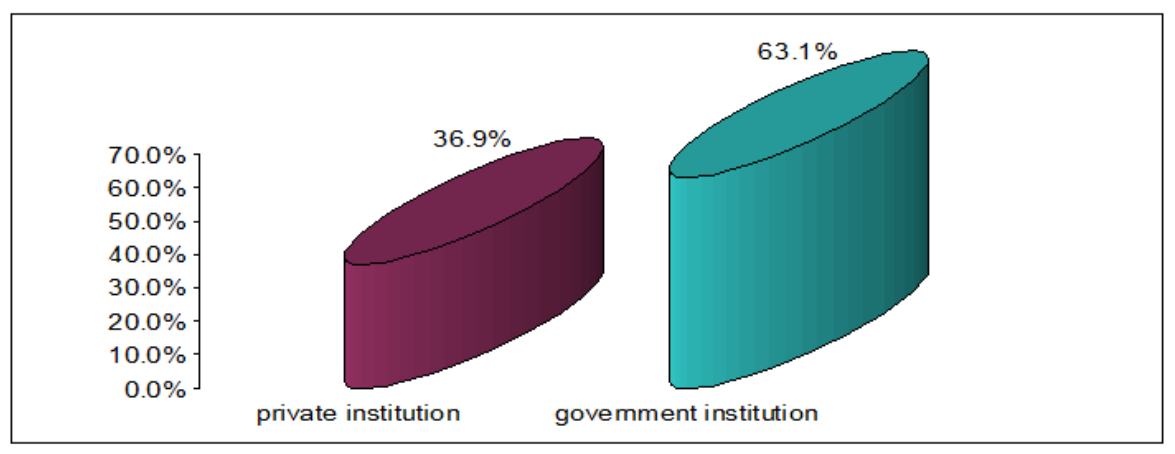

The statistics in figure (7) above show the participant's distribution according to graduation institutions, and it can be seen that the majority graduated from government institutions, with $63.1 \%$, whereas those graduated from private institutions represented about $36.9 \%$.

Figure (8) the nurses sample of the study distribution according to years of experience

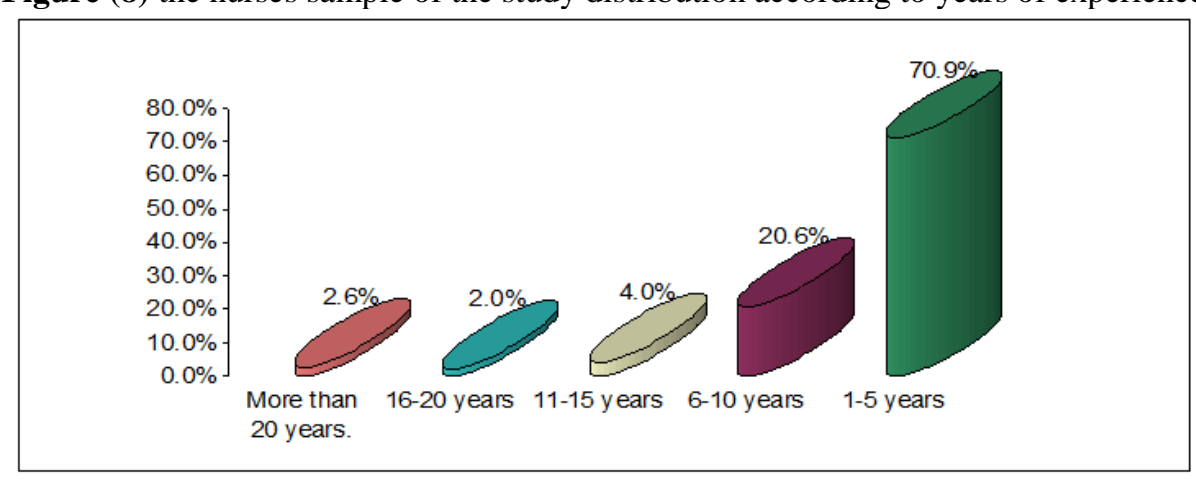

From the statistics in figure (8) it is evident that the majority of the sample have working experience between (1-5) years. 
Table 1. Perceptions of the nursing profession

\begin{tabular}{|c|c|c|c|c|c|c|c|}
\hline \multirow[b]{2}{*}{ Items } & \multicolumn{5}{|c|}{$\begin{array}{l}\text { Sample responses in percentages }(n= \\
\text { 350) }\end{array}$} & \multirow[b]{2}{*}{ 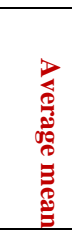 } & \multirow{2}{*}{$\begin{array}{l}5 \\
\frac{0}{2} \\
0 \\
0 \\
0 \\
0 \\
0 \\
0 \\
0 \\
0 \\
0\end{array}$} \\
\hline & 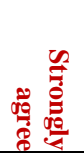 & 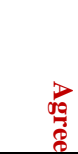 & 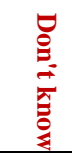 & 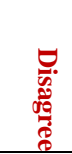 & 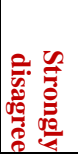 & & \\
\hline Humanitarian profession & 79.2 & 17.4 & 2.3 & 1.1 & 0.0 & 4.75 & SA \\
\hline Indispensable profession & 72.9 & 21.7 & 2.9 & 2.3 & 0.3 & 4.65 & SA \\
\hline Admirable job & 62.9 & 29.4 & 3.4 & 2.9 & 1.4 & 4.49 & SA \\
\hline Plays an important role in patient care & 59.3 & 31.2 & 6.6 & 2.6 & 0.3 & 4.47 & SA \\
\hline Contributes to effective health education & 57.1 & 33.2 & 5.7 & 1.7 & 2.3 & 4.41 & SA \\
\hline Supporting self-realization & 37.4 & 28.9 & 22.3 & 5.4 & 6.0 & 3.86 & SA \\
\hline Predominantly female profession & 33.7 & 27.7 & 7.7 & 20.0 & 10.9 & 3.53 & SA \\
\hline $\begin{array}{l}\text { Caring profession in which ethical standards } \\
\text { of care are maintained }\end{array}$ & 38.9 & 43.7 & 7.4 & 4.9 & 5.1 & 4.06 & Agree \\
\hline $\begin{array}{l}\text { Hard profession that does not receive enough } \\
\text { appreciation }\end{array}$ & 38.0 & 39.4 & 9.1 & 8.9 & 4.6 & 3.97 & Agree \\
\hline Opportunity to get personal growth & 27.4 & 41.4 & 10.9 & 9.4 & 10.9 & 3.65 & Agree \\
\hline Receives recognition from the community & 22.3 & 35.1 & 12.0 & 20.3 & 10.3 & 3.39 & Agree \\
\hline Allows nurses to make positive changes & 16.9 & 22.6 & 20.0 & 23.7 & 16.9 & 2.99 & Disagree \\
\hline Nurses make decisions about nursing care & 16.9 & 22.6 & 16.0 & 29.1 & 15.4 & 2.96 & Disagree \\
\hline Nurses follow doctors' orders without question & 10.0 & 15.1 & 14.0 & 39.1 & 21.7 & 2.53 & Disagree \\
\hline Does not require eligibility criteria & 6.0 & 13.4 & 14.6 & 41.1 & 24.9 & 2.35 & Disagree \\
\hline Equal to other disciplines & 11.1 & 16.6 & 8.9 & 28.9 & 34.5 & 2.41 & $\begin{array}{l}\text { Strongly } \\
\text { disagree }\end{array}$ \\
\hline $\begin{array}{l}\text { Nurses spend most of their time in non-nursing } \\
\text { care }\end{array}$ & 5.4 & 8.9 & 10.3 & 22.0 & 53.4 & 1.91 & $\begin{array}{l}\text { Strongly } \\
\text { disagree }\end{array}$ \\
\hline $\begin{array}{l}\text { I am satisfied with the career ladder and } \\
\text { financial benefits of nursing }\end{array}$ & 5.7 & 13.7 & 4.6 & 27.7 & 48.3 & 2.01 & $\begin{array}{l}\text { Strongly } \\
\text { disagree }\end{array}$ \\
\hline $\begin{array}{l}\text { I think nursing would be a great profession for } \\
\text { my children }\end{array}$ & 12.3 & 15.4 & 16.9 & 16.6 & 38.9 & 2.46 & $\begin{array}{l}\text { Strongly } \\
\text { disagree }\end{array}$ \\
\hline Similar to the servants' job & 16.6 & 22.9 & 12.6 & 18.0 & 30.0 & 2.78 & $\begin{array}{l}\text { Strongly } \\
\text { disagree }\end{array}$ \\
\hline The grand & & & & & & 3.38 & \\
\hline
\end{tabular}

The statistics in the above table show the nurses' perceptions of the nursing profession. In general, it can be seen that nurses' perceptions of the nursing profession tend to vary with the mean value reaching 3.38 , with a standard deviation of 0.42 . The elements that the participants perceived with a high and positive rating included the following: nursing is a humanitarian profession, is an indispensable profession in any society, is an admirable job, and plays an important role in patient care. In addition, they perceived the nursing profession as helpful in providing effective education and promoting health.

Furthermore, nurses had negative perceptions of various elements of their profession, such as nurses following doctors' orders without questioning them, the suitability of the nursing profession for their children, that the nursing profession is equal to other professions, that nursing does not have eligibility criteria (i.e., anyone can be a nurse), satisfaction with the career ladder and financial benefits of nursing, and nurses devoting most of their time to non-nursing care. In particular, they were never satisfied with the career ladder and financial benefits of nursing.

Perceptions of other issues related to the nursing profession

Table 2. Perceptions of nurses' feelings about their profession

\begin{tabular}{|l|c|c|}
\hline \multicolumn{1}{|c|}{ Variables } & Frequency & Percentage \\
\hline Proud & 207 & 59.1 \\
\hline Shy & 24 & 6.9 \\
\hline Frustrated & 39 & 11.1 \\
\hline Happy & 41 & 11.8 \\
\hline Satisfied & 39 & 11.1 \\
\hline Total & 350 & 100.0 \\
\hline
\end{tabular}

As Table 2 indicates, when the participants were asked to express their feelings about being nurses, $59.1 \%$ felt proud, $11.8 \%$ felt happy, $11.1 \%$ expressed frustration about nursing, $11.1 \%$ considered themselves satisfied, and only $6.9 \%$ felt shy.

Table3. Perceptions regarding intention to leave the nursing profession

\begin{tabular}{|l|c|c|}
\hline \multicolumn{1}{|c|}{ Responses } & Frequency & Percentage \\
\hline Yes & 212 & 60.6 \\
\hline No & 138 & 39.4 \\
\hline Total & 350 & 100.0 \\
\hline
\end{tabular}


The results in Table 3 clearly indicate that $60.6 \%$ of nurses intend to leave the nursing profession, suggesting that there are serious influential factors underpinning this trend. Therefore, recognizing these factors is critical for the Ministry of Health, as there is already a continuous shortage of nursing staff in the government hospitals.

Table 4. Perceptions regarding where nurses would like to be transferred

\begin{tabular}{|l|c|c|}
\hline \multicolumn{1}{|c|}{ Responses } & Frequency & Percentage \\
\hline Another hospital & 42 & 12.0 \\
\hline Public health center & 98 & 28.0 \\
\hline Outside the ministry of health & 72 & 20.6 \\
\hline Total & 212 & 60.6 \\
\hline
\end{tabular}

From the results in Table 4 , it can be seen that $28 \%$ of the nurses would transfer to a public health center, whereas $20.6 \%$ would transfer completely outside the Ministry of Health, and $12 \%$ would transfer to another hospital.

Table 5. Perceptions regarding the reasons why they intend to leave the profession

\begin{tabular}{|l|c|c|}
\hline \multicolumn{1}{|c|}{ Reasons } & Frequency & Percentage \\
\hline Work environment & 52 & 24.5 \\
\hline Low salary and allowances & 47 & 22.2 \\
\hline Rewards and incentives & 37 & 17.5 \\
\hline Practical development & 34 & 16.0 \\
\hline Public perceptions of the nursing profession & 24 & 11.3 \\
\hline relationship with other disciplines & 18 & 8.5 \\
\hline Total & 212 & 100.0 \\
\hline
\end{tabular}

The results in Table 5 above show the most important reasons causing nurses to leave the nursing profession, and it is evident that the work environment is the most important one, with $24.5 \%$ confirming this, followed by the low salary and allowances, with $22.2 \%$. The third reason is rewards and incentives, with $17.5 \%$. This is followed by the nurses' practical development, with $16.0 \%$ and the public perception of the nursing profession, at $11.3 \%$, and lastly, relationship with other disciplines, at $8.5 \%$.

Table 6. Perceptions of the factors that can prevent nursing staff turnover

\begin{tabular}{|l|c|c|}
\hline \multicolumn{1}{|c|}{ Factors } & Frequency & Percentage \\
\hline Work environment & 143 & 40.9 \\
\hline Increase salary and allowances & 67 & 19.1 \\
\hline Rewards and incentives & 55 & 15.7 \\
\hline Practical development & 49 & 14.0 \\
\hline Public perceptions of the nursing profession & 19 & 5.4 \\
\hline Relationship with other disciplines & 17 & 4.9 \\
\hline Total & 350 & 100.0 \\
\hline
\end{tabular}

The results in Table 6 above show that the most important factors for retaining nurses, in order, are the work environment (40.9\%), increase in salary and allowances $(19.1 \%)$, rewards and incentives (15.7\%), practical development $(14.0 \%)$, public perceptions of the nursing profession $(5.4 \%)$, and the relationship with other disciplines $(4.9 \%)$.

\section{Testing significant differences}

Table (7) shows the results of T-Test statistics to measure the variations between nurses satisfaction with career ladder and financial benefits of nursing profession related to employment systems.

\begin{tabular}{|l|c|c|c|c|c|r|}
\hline \multicolumn{1}{|c|}{ Employment systems } & $\mathbf{N}$ & Mean average & Stdv. & Df & T-Test & P-value. \\
\cline { 1 - 5 } Civil service & 230 & 1.87 & 1.20 & 348 & -2.79 & 0.006 \\
\cline { 1 - 3 } Autonomously operated health facilities, & 120 & 2.27 & 1.35 & & & \\
\hline
\end{tabular}

From the above table, the study found that there are significant variations in nurses' levels of satisfaction with their career ladder and the financial benefits of the nursing profession related to employment systems. we noticed that, the value of T-test statistics is equal to (-2.79) which is statistically significant as the P-value is less than (0.01). It is obvious that the variations are owing to the nurses employed in autonomously operated health facilities, which indicates that those nurses feel more satisfied than those employed in the civil service system. The results do not show any statistically significant differences between sample responses regarding satisfaction with the career ladder and financial benefits of the nursing profession related to gender, age classification, educational level, marital status, or years of experience. In addition, there are no statistically significant variations between male and female nurses regarding their perceptions in relation to nursing being a respectable profession, suggesting that the gender difference should not be regarded as causing any variations between nurses. 
Table 8. Suggestions regarding improving nurses' perceptions of nursing as a profession (Open ended question)

\begin{tabular}{|c|c|c|c|}
\hline \multicolumn{2}{|r|}{ Suggestions of Nurses } & Frequency & Percent \\
\hline 1 & $\begin{array}{l}\text { Improvement of working conditions } \\
\text { Improving the career ladder, increasing salaries, incentives, and morale for nurses, and } \\
\text { providing special allowances, such as infection, scarcity allowances, and transportation } \\
\text { allowances }\end{array}$ & 89 & 24 \\
\hline 2 & Reducing the work hours to six hours; implementing four or six shifts in the day & 45 & $12 \%$ \\
\hline 3 & Providing daycare for nurses' children & 26 & $7.1 \%$ \\
\hline 4 & $\begin{array}{l}\text { Giving nursing staff the rights and advantages that contribute to the improvement of job } \\
\text { performance and job ethics, as nursing is a humanitarian profession }\end{array}$ & 25 & $6.9 \%$ \\
\hline 5 & Increasing the number of nurses to decrease work pressure and load & 24 & $6.6 \%$ \\
\hline 6 & $\begin{array}{l}\text { Respect for the nursing profession and dealing with nurses as human beings (especially on } \\
\text { the part of physicians) }\end{array}$ & 24 & $6.3 \%$ \\
\hline 7 & $\begin{array}{l}\text { Replacing the current nursing administration with one that is responsible; applying justice } \\
\text { to improve nursing management }\end{array}$ & 23 & $6.3 \%$ \\
\hline 8 & Increase the society and cultural recognition of the importance of the nursing profession & 20 & $5.4 \%$ \\
\hline 9 & $\begin{array}{l}\text { Give educational opportunities for nurses to complete their university education and } \\
\text { higher studies }\end{array}$ & 18 & $4.9 \%$ \\
\hline 10 & Equalization of nursing staff with staff in other professions & 17 & $4.6 \%$ \\
\hline 11 & $\begin{array}{l}\text { Nurses should contribute to change by showcasing their abilities and imposing respect for } \\
\text { the profession on the society, patients and medical staff. }\end{array}$ & 15 & $4.0 \%$ \\
\hline 12 & Caring for the families of nursing staff & 14 & $3.7 \%$ \\
\hline 13 & $\begin{array}{l}\text { Allow the nurses their right to child care or increase the days of rest from six days a } \\
\text { month }\end{array}$ & 11 & $2.9 \%$ \\
\hline 14 & Punishment for irresponsible staff and appreciation for active staff & 9 & $2.3 \%$ \\
\hline 15 & Workshops to improve nurses' performance. & 8 & $2.0 \%$ \\
\hline
\end{tabular}

\section{Discussion}

The main purpose of this research was to evaluate how professional nurses perceive their profession in the three largest government hospitals in Jeddah province, and to investigate the reasons why nurses leave the profession. Most of the participants in this study (38.3\%) were in the youngest age group of 26-30 years, indicating that the nursing staff working in the government hospitals could contribute effectively to the improvement of the services introduced to patients, if they were fully trained and qualified, and being respected both inside and outside the hospital.

The results of this study reveal that the majority of the sample perceived nursing positively. Indeed, $96.6 \%$ of participants viewed the nursing profession as a humanitarian career based on a set of core values and principles, $94.6 \%$ considered it an indispensable and essential career, $92.3 \%$ stated that the community considers it to be a respectable and admirable career, $90.5 \%$ believed it to be important for providing care to the patients, and $90.3 \%$ thought it had a key role in improving health through health education. These results are consistent with the findings of [27] that $99.1 \%$ of the sample perceived the nursing profession positively and as giving them a chance to serve humanity. In addition, [27] found $69.6 \%$ of the participants considered the nursing profession as a source of attaining recognition within the community, while another $69.4 \%$ perceived nursing as a dignified and respectful profession. [28] obtained a similar result—namely, that $56 \%$ of nurses had a positive perception of nursing.

The sample in this study believed that nurses take advantage of their time in delivering nursing care, and they declared that the nursing profession is not an easy profession, and thus should require the fulfillment of certain criteria. Most participants (59.1\%) felt pleased and proud when they were talking about the nursing profession. This finding is similar to that of [29] that $80.9 \%$ of participants expressed pride when talking to others about their career. Although the nurses in this study perceived the nursing profession positively and discussed it proudly, $76.0 \%$ confirmed that they were not satisfied with the career ladder and financial benefits of the career. Therefore, there are statistically significant variations in the sample's responses regarding their satisfaction with their career ladder and financial benefits of the profession related to employment status. The researcher could attribute the variations to the nurses employed in an autonomously operated health facilities, as the career ladder in the operational program rises higher than that in the civil service. In addition, the nurses in this study connected the desire to leave their work to the low salaries and lack of incentives. These results correspond to those of [22], where $77.6 \%$ of the sample believed that nursing was not a profession with high financial rewards. This result confirmed by [18], who found that in general, nurses were dissatisfied with the nursing work. 
Furthermore, the participants in the present study indicated that a nursing career was not appropriate for their children. This indicates that they were not sufficiently satisfied with the profession to believe that their children should pursue nursing career. A South African study found a similar result, where just $43.6 \%$ of the participants wanted their children to become nurses, with the remainder of the sample disagreeing [10]. In addition, [10] reported that nursing is still viewed as a female oriented profession, which is consistent with the present study, where $61.4 \%$ of the sample saw a nursing career as a feminine profession. Although most of the participants in the study perceived the nursing profession positively, the results reveal that $60.6 \%$ of the nurses intend to leave the nursing profession, whereas $39.4 \%$ intend to remain in the profession, $28 \%$ plan to transfer their services to public health centers, $20.6 \%$ intend to transfer outside the Ministry of Health, and $12.0 \%$ intend to transfer to another hospital.

The finding of this study do not align with those of a similar study conducted by [27], who stated that the majority of the nurses showed no interest in changing their profession. Similar findings were reported by [22], who found that $80 \%$ of nurses had a positive image of the profession and had not thought about leaving their job, and only $29.4 \%$ held a negative view and expressed the intention to leave the job. According to the results of this study, the working environment was the most important reason for leaving the nursing profession and also the most important factor in retaining nurses. These results are in agreement with the conclusion reached by [30] in her research on the "Effects of Work Environments on Nursing and Patient Outcomes," which showed that a work environment characterized by structural and psychological empowerment factors may enhance the quality of patient care, reduce patient risk, and increase nurses' job satisfaction. [31] found a relationship between work environment and nurses' stress and burnout.

However, regarding those who want to leave the nursing profession, the results may indicate that the nurses in the sample were not satisfied with the working conditions of the nursing career, rather than the nursing practice itself. In their investigation into the link between the shortage of Saudi nurses and socio-cultural factor within Saudi literature [32] found that these factors influenced the prevailing negative images and perceived low status of nursing. [32] also, shows that the community's perceptions, family disagreements, cultural and communal values, long working hours, mixing with members of the opposite gender, and worries about not being "marriageable" are the main reasons why Saudis do not choose nursing as a career. Hospitals face a significant challenge in their ability to find and keep highly qualified and experienced nurses; therefore, each hospital should prepare a retention plan to prevent or reduce the turnover rate of their nurses, taking into account the provision of a suitable work environment for the staff.

\section{Conclusion}

In conclusion, this research was conducted essentially to study professional nurses' perceptions of the nursing profession in the three largest government hospitals in Jeddah province. The main objective of this study was to assess the reasons why nurses would leave the nursing profession and determine the factors that can help to retain them. The study followed a quantitative approach, using a survey method. The sample consisted of 350 nurses. Most participants perceived nursing positively, with $59.1 \%$ feeling proud to be part of the nursing profession. However, $76.0 \%$ confirmed that they were not satisfied with the career ladder or with the financial benefits of nursing. Moreover, 55.5\% believed that the nursing profession would not be suitable for their children. The participants in this study reported that the work environment was the most important reason behind nurses' decision to leave the profession and therefore in retaining them.

\section{The researcher recommends the following:}

\section{Recommendations}

1. Improve the working conditions by focusing on improving the psychological and physical environment.

2. Provide emotional support to nurses by enhancing the community's perceptions of the importance of the nursing profession, because if this changes, nurses will encourage their children to pursue a career in the same field and remain in the field, thus increasing the number of nurses and reducing the workload.

3. To retain nurses, it is necessary to improve their perceptions of their profession and ensure that others respect the nursing profession and deal with nurses as human beings. Moreover, nursing staff should be given rights and advantages that contribute to the development of their job performance and enable them to make changes on their own.

4. It is essential to develop strategies to improve the leadership in nursing. It is very important for new nurses to have the opportunity to progress into leadership and management positions after undergoing training and preparation.

5. Nurses should have the opportunity to continue their studies to attain bachelor's, master's, and doctoral degrees in nursing, and nursing education and training should be developed according to the needs of the nurses. 
6. Create incentive programs for nurses who are working in hospitals to increase their loyalty to the nursing profession and prevent staff turnover. In addition, hospitals should take disciplinary action against irresponsible staff members and show more appreciation for the deserving ones.

7. Improve the financial benefits of the nursing career by developing the career ladder for nurses and providing allowances for nurses working in critical care departments. In addition, provide general allowances for all nurses working in hospitals, such as an accommodation allowance, infection control allowance, shifts allowance, and an increased transportation allowance.

\section{Acknowledgement}

I would like to thank Mrs. Eman Saeed Badokhon Director of Nursing Administration in Jeddah Provence for her unstinting support. My genuine appreciation for nursing administration and nursing staff in King Fahd Hospital, King Abdulaziz Hospital and Althager Hospital for their participation in distribution, completion and collection of questionnaires. Finally, my special appreciation to my family, my husband and my children for their help and encouragement.

\section{References}

[1] C.A. Awynd, Current factors contributing to professionalism in nursing, Journal of Professional Nursing, 19(5), 2003, 251-261.

[2] Ministry of Health, Statistics book of the Ministry of Health (Kingdom of Saudi Arabia, 2015 ,26-27. Accessed 20 December 2015. Available from http://www.moh.gov.sa/Pages/Default.aspx en pdf.

[3] World Health Organization, Global standards for the initial education of professional nurses and midwives , 2009. Available from http:// www. who. int/ hrh/ nursing_midwifery/hrh_global_standards_education.pdf.

[4] S. Abu-Zinadah, The current situation of nursing in Saudi Arabia (Saudi Council for Health Specialties, 2006 . Available at: www.nurse.scfhs.org.

[5] Ministry of Health, Nursing administration in the Jeddah region. Nursing Transfer Requests Report, 2015.

[6] M. Al Yami and R. Watson, An overview of nursing in Saudi Arabia, Journal of Health Specialties, 2(1), 2014,11

[7] K. Tomajan, Advocating for nurses and nursing, OJIN: The Online Journal of Issues in Nursing, 17(1), 2012, Manuscript 4.

[8] English Oxford Living Dictionaries ,2017. Available at: Https:// en. oxforddictionaries. com/ definition/ perception.

[9] N.A. Al-Onazi and M.A. Omar, Factors affecting the retention of nurses, Saudi Medical Journal, 34(3), 2013, $288-294$.

[10] A. Meiring, The image of nurses as perceived by the South African public, 2011. Available at: http://upetd.up.ac.za/thesis/available/etd-06222011-113326/

[11] T. Miyuki, The relationship between images of nursing and person-environment fit, doctoral diss, School of Nursing, University of Melbourne, Melbourne, 2005.

[12] E.J. Sullivan, Becoming influential. A guide for nurses (Upper Saddle River, NJ: Pearson Education, 2004).

[13] L. Gazzaz, Saudi nurses' perceptions of nursing as an occupational choice: A qualitative interview study, doctoral diss, Faculty of Medicine and Allied Health Science School of Nursing, University of Nottingham, Nottingham, 2009.

[14] B.I.J.M. van der Heijden, K. van Dam, and H.M. Hasselhorn, Intention to leave nursing: The importance of interpersonal work context, work-home interference, and job satisfaction beyond the effect of occupational commitment, Career Development International, 14(7), 2009, 616-635. DOI: http://dx.doi.org/10.1108/13620430911005681.

[15] M. Flinkman, U. Isopahkala, and S. Salantera, Young registered nurses' intention to leave the profession and professional turnover in early career: A qualitative case study, International Scholarly Research Notices, Article ID 916061, $2013,12$.

[16] P.P. Gerber, P.S. Nel, and P.S. Van Dyk, Human resource management (Johannesburg: Internal Thomson Publishing, 1998)

[17] R. Markey, K. Ravenswood, and D. Webber, The impact of the quality of the work environment on employees' intention to quit (University of the West of England, Available http://www2.uwe.ac.uk/faculties/BBS/BUS/Research/economics2012/1221,3-4.

[18] M. Alshmemri, Job satisfaction of Saudi nurses working in Saudi Arabian public hospitals, doctoral diss., Health Sciences, RMIT University, 2014.

[19] J. Trybou, S. Malfait, and P. Gemme, Nursing staff and their team: Impact on intention to leave, International Council of Nurses, Ghent University, Ghent, Belgium, 2015.

[20] S. Cohen, Reflections on the image of nursing. Benchmarking Report, 2008. Available at http:// www .hcpro .com/content/222604.pdf.

[21] A. Finkelman, Leadership and management for nurses. Core competencies for quality care (Upper Saddle River, NJ: Pearson Education, 2012).

[22] S. Varaei, M. Vaismoradi, M. Jasper, and S. Faghihzadeh, Iranian nurses' self-perception - factors influencing nursing image, Journal of Nursing Management, 20(4), 2012, 551-560.

[23] A. Hajibagheri and I. Fini, Mouth care in patients receiving mechanical ventilation, Nursing and Midwifery Studies, 1(2), 2012, 5161.

[24] C.R. Kothari, Research methodology, methods and techniques (New Delhi: Wiley Eastern Limited, 1989).

[25] H. Maylor and K. Blackmon, Researching business and management (New York, NY: Palgrave, 2005).

[26] Creative Research System, 2016. Available at: http://www.survey system.com/sscalc.htm.

[27] B.P. Anurag, K. Jasbir, S. Neeraj, and K.S. Suresh, Future nurses' perception towards profession and carrier plans: A cross sectional survey in state Punjab, Nursing and Midwifery Research Journal, 7(4), 2011, 179-182.

[28] L. Wondwossen, Assessment of nurses' perception towards nursing profession in public hospitals under Addis Ababa Health Bureau, master's diss., Addis Ababa University, Addis Ababa, Ethiopia, 2011.

[29] I.A.T. Al-Jarrah, Associate nursing students' perceptions toward nursing profession in Jordan, European Scientific Journal, 9(6), 2013, 153-156.

[30] N.M. Purdy, Effects of work environments on nurse and patient outcomes, Electronic doctoral diss., University of Western Ontario, London, ON Canada, 2011.

[31] G.P. Ojekou and O.T. Dorothy, Effect of work environment on level of work stress and burnout among nurses in a teaching hospital in Nigeria, Open Journal of Nursing, 5, 2015, 948-955.

[32] S. Lamadah and H.Y. Sayedm, Challenges facing nursing profession in Saudi Arabia. Journal of Biology, Agriculture and Healthcare, 4(7), 2014, 20-23. 